\title{
Gas Storage Technology Consortium
}

\author{
Technical Quarterly Progress Report for \\ January 1, 2007 - March 31, 2007
}

By

Joel L. Morrison

and

Sharon L. Elder

May 24, 2007

Work Performed Under DOE Cooperative Agreement DE-FC26-03NT41779

\section{Submitting Organization:}

The Pennsylvania State University

The Energy Institute

C211 Coal Utilization Lab

University Park, PA 16802 


\section{DISCLAIMER}

This report was prepared as an account of work sponsored by an agency of the United States Government. Neither the United States Government nor any agency thereof, nor any of their employees, makes any warranty, express or implied, or assumes any legal liability or responsibility for the accuracy, completeness, or usefulness of any information, apparatus, product, or process disclosed, or represents that its use would not infringe privately owned rights. Reference herein to any specific commercial product, process, or service by trade name, trademark, manufacturer, or otherwise does not necessarily constitute or imply its endorsement, recommendation, or favoring by the United States Government or any agency thereof. The views and opinions of the authors expressed herein do not necessarily state or reflect those of the United States Government or any agency thereof. 


\section{ABSTRACT}

Gas storage is a critical element in the natural gas industry. Producers, transmission and distribution companies, marketers, and end users all benefit directly from the load balancing function of storage. The unbundling process has fundamentally changed the way storage is used and valued. As an unbundled service, the value of storage is being recovered at rates that reflect its value. Moreover, the marketplace has differentiated between various types of storage services and has increasingly rewarded flexibility, safety, and reliability. The size of the natural gas market has increased and is projected to continue to increase towards 30 trillion cubic feet (TCF) over the next 10 to 15 years. Much of this increase is projected to come from electric generation, particularly peaking units. Gas storage, particularly the flexible services that are most suited to electric loads, is crucial in meeting the needs of these new markets.

To address the gas storage needs of the natural gas industry, an industry-driven consortium was created - the Gas Storage Technology Consortium (GSTC). The objective of the GSTC is to provide a means to accomplish industry-driven research and development designed to enhance the operational flexibility and deliverability of the nation's gas storage system, and provide a cost-effective, safe, and reliable supply of natural gas to meet domestic demand.

This report addresses the activities for the quarterly period of January1, 2007 through March 31, 2007. Key activities during this time period included:

- Drafting and distributing the 2007 RFP;

- Identifying and securing a meeting site for the GSTC 2007 Spring Proposal Meeting;

- Scheduling and participating in two (2) project mentoring conference calls;

- Conducting elections for four Executive Council seats;

- Collecting and compiling the 2005 GSTC Final Project Reports; and

- Outreach and communications. 
TABLE OF CONTENTS

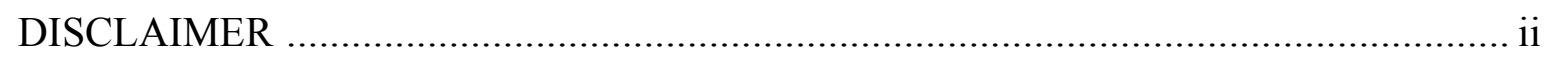

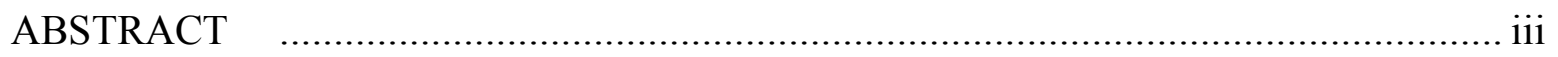

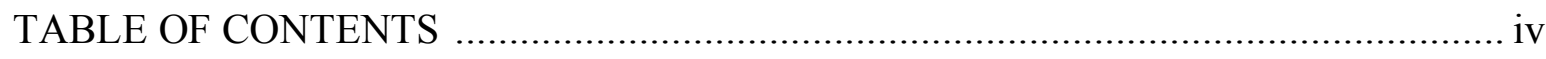

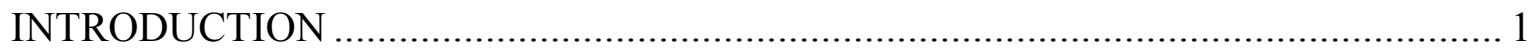

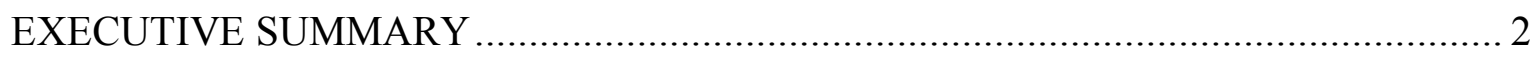

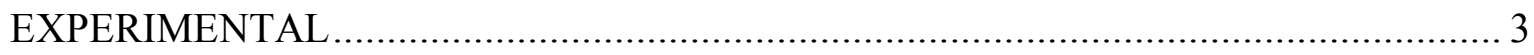

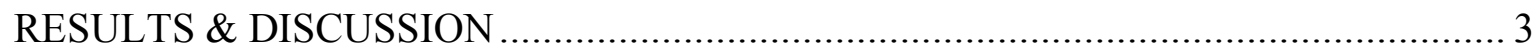

Request for Proposals (RFP) …………………………………………………………3

Spring Proposal Meeting.................................................................................................

Project Mentoring Conference Calls ........................................................................................ 4

New Executive Council Members..........................................................................................

2005 Project Reports ...............................................................................................

Outreach and Communications ……………………………………………………....

Planned Activities for Next Reporting Period .....................................................................

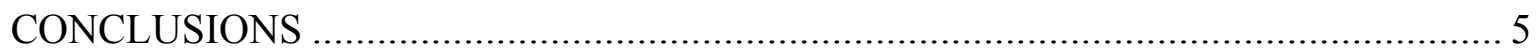

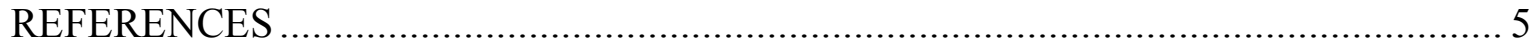

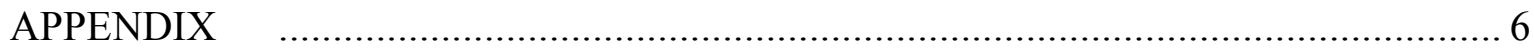

Appendix A - Request for Proposals ……………………………….... 7 


\section{INTRODUCTION}

Gas storage is a critical element in the natural gas industry. Producers, transmission and distribution companies, marketers, and end users all benefit directly from the load balancing function of storage. The unbundling process has fundamentally changed the way storage is used and valued. As an unbundled service, the value of storage is being recovered at rates that reflect its value. Moreover, the marketplace has differentiated between various types of storage services and has increasingly rewarded flexibility, safety, and reliability. The size of the natural gas market has increased and is projected to continue to increase toward 30 trillion cubic feet (TCF) over the next 10 to 15 years. Much of this increase is projected to come from electric generation, particularly peaking units. Gas storage, particularly the flexible services that are most suited to electric loads, is crucial in meeting the needs of these new markets.

To address the gas storage needs of the natural gas industry, an industry-driven consortium was created - the Gas Storage Technology Consortium (GSTC). The objective of the GSTC is to provide a means to accomplish industry-driven research and development designed to enhance the operational flexibility and deliverability of the nation's gas storage system, and provide a cost-effective, safe, and reliable supply of natural gas to meet domestic demand. Consortium technology development is conducted in the general areas of well-bore and reservoirs, operations, mechanical, and salt caverns. Consortium members elect an executive council that is charged with reviewing projects for consortium co-funding. Proposals must address improving the production performance of gas storage and provide significant cost sharing. The process of having industry members develop, review, and select projects for funding ensures that the GSTC conducts research that is relevant and timely to the industry. Co-funding of projects using external sources of funding is sought to ensure that GSTC funds are highly leveraged. 


\section{EXECUTIVE SUMMARY}

This report summarizes the important accomplishments during the period of January 1, 2007 through March 31, 2007. The GSTC was established under contract to The Pennsylvania State University from the U.S. Department of Energy (DOE), National Energy Technology Laboratory (NETL), in June 2004. The agreement provides the Pennsylvania State University with the overarching management responsibilities for the GSTC.

Key activities for this reporting period included the following:

Request for Proposals

The Request for Proposals (RFP) was drafted and released. Proposals are due on May 3, 2007.

Spring Proposal Meeting

The Spring Proposal Meeting to hear all requests for funding will be held on May 1617, 2007 at the Buffalo Marriott Niagara, Amherst, NY.

\section{Project Mentoring Conference Calls}

Two conference calls were scheduled and conducted, as follows:

- Effects of Tensile Loading on the Remaining Strength of a Corroded Casing (Keifner and Associates), March 14, 2007, and

- State-of-the-Art Assessment of Alternative Casing Repair Methods (Edison Welding Institute), March 26, 2007.

New Executive Council Members

The GSTC Technical Advisory Committee elected four (4) representatives to serve on the Executive Council for 2007-2008.

\section{Project Reports}

The 2005 Project Reports are due and scheduled for distribution during the next quarter. To date, five reports have been received and approved.

\section{Outreach and Communications}

The GSTC Insider e-newsletter was drafted for release in April 2007. 


\section{EXPERIMENTAL}

A description of experimental methods is required by the DOE for all quarterly technical progress reports. In this program, Penn State is responsible for establishing and managing an industry-driven underground gas storage consortium. Technology development research awards are made on a competitive basis. Technical reports from the individual researchers are required to contain experimental discussion sections and are submitted to consortium members and the DOE for review. Therefore, this section is not applicable to the Penn State contracted activities.

\section{RESULTS \& DISCUSSION}

This report addresses the activities for the reporting period from January 1, 2007 through March 31, 2007. Key activities during this time period included:

- Drafting and releasing the 2007 Request for Proposals (RFP)

- Secure facility, schedule and draft plans for the 2007 Spring Proposal Meeting

- Scheduling and participating in project mentoring conference calls for two projects;

- Electing representatives for four Executive Council seats;

- 2005 Final Project Reports;

- Outreach and communications.

\section{Request for Proposals (RFP)}

The 2007 Request for Proposals was drafted and released for proposals due May 3, 2007. The funding cycle will be from August 1, 2007 to July 31, 2008. Proposals are being solicited in the following research focus area:

- Mechanical

- Well-bore and reservoir

- Operations

- Salt cavern

The Pipeline Research Council International (PRCI) will be providing cost share and have identified the following topics as priority areas: 
- Deliverability maintenance and enhancement

- Base gas reduction

- Improved assessment of wellbore tubulars

- Reduced well workover costs

The RFP is attached as Appendix A.

\section{Spring Proposal Meeting}

The 2007 Spring Proposal Meeting to hear all proposals received in response to the RFP will be May 16-17, 2007 at the Buffalo Marriott Niagara, Amherst, New York. In addition to presentations from all project submissions, a strategic planning session is being planned. The final plans are being drafted.

\section{Project Mentoring Conference Calls}

Members of two projects participated in the conference call mentoring sessions during this quarter. For each conference call, anywhere from six to eleven people participated. The two projects and the date of each conference call were:

- Effects of Tensile Loading on the Remaining Strength of a Corroded Casing (Keifner and Associates), March 14, 2007, and

- State-of-the-Art Assessment of Alternative Casing Repair Methods (Edison Welding Institute), March 26, 2007.

\section{New Executive Council Members}

The GSTC Technical Advisory Committee elected four (4) representatives to serve on the Executive Council for 2007-2008:

- Gregory Theirl, Dominion Delivery

- Todd Thomas, NW Natural

- George Hodges, Panhandle Energy

- James Mansdorfer, Southern California Gas

The Executive Council members who will continue to serve until the end of 2007 are:

- Allen Bues, AMEREN Corp.

- Douglas Elenbaas, El Paso Corp.

- Timothy Habovick, Equitrans, LP

- David Burnett, Texas A\&M University

- Richard Stocke, Texas Gas Transmission, LLC 


\section{Project Reports}

The 2005 projects ended December 31, 2006. The final project reports are now due and are being compiled for distribution during next quarter.

\section{Outreach and Communications}

The GSTC Insider electronic newsletter was drafted for release the first week of April 2007.

\section{Planned Activities for Next Reporting Period}

During the next quarter the GSTC will:

- Complete final plans and hold the 2007 Spring Proposal Meeting;

- Identify projects for 2007 ;

- Schedule and continue mentoring team conference calls for 2006 projects;

- Compile and release the 2005 GSTC project reports;

- Draft and release another online newsletter; and

- Continue to update and improve the GSTC web site.

\section{CONCLUSIONS}

During this reporting period, the GSTC released the RFP for 2007 projects. The meeting site and final plans for the GSTC Spring Meeting have been finalized. Two mentoring team conference calls were held. The GSTC elected four representatives to serve on the Executive Council for 2007-2008. Through these efforts, the GSTC has laid a solid foundation for continued membership growth and industry-relevant technology transfer.

\section{REFERENCES}

A listing of referenced materials is required by the DOE for each quarterly technical progress report. However, this technical progress report for the GSTC did not utilize any reference materials during this reporting period. 
APPENDIX A

Request for Proposals 


\section{The \\ Gas Storage Technology Consortium}

Request for Proposals

For 2007

Submission Deadline:

May 3, 2007 (4:00 pm EST) 


\begin{abstract}
APPLICANT ELIGIBILITY
Competition is open to all current Full and University Members of the Gas Storage Technology Consortium (GSTC). The GSTC Executive Council will not review proposals without a fully executed membership agreement in place. New memberships are accepted throughout the year. Membership information and applications can be found on the GSTC website at http://www.energy.psu.edu/gstc. Proposals received from members whose dues are not current, or whose membership agreement is not fully executed will be returned without review.
\end{abstract}

University employees eligible to serve as principal investigators for proposals submitted to the consortium are:

Full-time regular tenure-track or regular faculty, and;

Persons with the title of Research Assistant, Associate, Scientist or Senior Scientist.

\title{
INSTITUTION COMMITMENT
}

Each proposal must be signed by an official of the company or university who is authorized to commit the company/institutional resources to the project. The name of the Applicant's authorized official shall be entered in the appropriate space shown on the cover page (Attachment B).

\section{RESEARCH FOCUS AREAS}

The mission of the GSTC is to assist in the development, demonstration and commercialization of technologies to improve the integrity, flexibility, deliverability, and cost-effectiveness of the nation's underground natural gas/hydrocarbon storage facilities. Projects selected for funding will be based on those that best accomplish the Consortium goals. Proposals in this funding cycle are being solicited from GSTC Full and University Members in the following focus areas:

\section{Mechanical}

Examples include, but are not limited to, investigations that address pipe and well casing integrity, the improvement of downhole leak detection, the development of new casing evaluation tools, the development/ evaluation of advanced metallurgy/ materials for use in well casing and casing repairs, cement bonding, delta-temperature effects on casing, use of "smart pipe" concepts for well casing, corrosion mitigation and quantification, removal 
techniques for scales, fines, salts, asphalts, and techniques to remediate damage through stimulation/ recompletion/ workover of existing wells.

\section{Well-bore and Reservoir}

Examples include, but are not limited to, investigations that address reservoir characterization, consider new approaches to modeling of gas cycling and inventory verification, develop techniques to maintain and improve injectivity and deliverability, and expand existing aquifers and reservoirs.

\section{Operations}

Examples include, but are not limited to, investigations that address handling of produced water, techniques to minimize/mitigate water encroachment, cost effective multiphase wellhead measurement systems, design criteria for facility sizing to meet variable demand, and best practices associated with product quality shipped/delivered. In addition, applied research into the development/ evaluation of low-cost salt inhibitors to mitigate salt

precipitation within the reservoir, well, and pipeline systems are being sought.

\section{Salt Cavern}

Examples include, but are not limited to, investigations that address salt cavern stability and growth rates, interconnectivity and best practices techniques for management of caverns.

The four focus areas and their corresponding examples are to be used as general guidelines for applicants. The Pipeline Research Council International (PRCI) is providing cost share to GSTC. The PRCI has identified the following topics as their funding priority areas:

Deliverability maintenance and enhancement - reduce time and cost to deliver improved storage performance (applicable to existing well maintenance/enhancement or new wells)

- Lower cost, long lasting damage remediation, precipitate removal

- Enhanced coiled tubing delivered technology

- Improved downhole sensing devices for determining reservoir parameters and performance

- Improved reservoir characterization for quick, low-cost optimization analysis

- Develop protocol for identification and remediation of damage mechanisms impacting brine disposal wells

Visit the GSTC web site - http://www.energy.psu.edu/gstc to download this and other GSTC documents. Last modified on March 5, 2007. 
- Improved technology for eliminating gas hydrates in wells and pipeline systems. Must be non-damaging to reservoir and pipe.

- Improved wellhead separation/filtration methods for removing produced brines and eliminating undesirables from being injected into storage. Need low maintenance cost solutions.

\section{Base gas reduction}

- Conversion to top gas capacity

- Replacement with inert gas

\section{Improved assessment of wellbore tubulars}

- Improved MFL (magnetic flux leakage) defect characterization

- Other technology (non-MFL) for defect detection

- Improved understanding of remaining strength in wellbore casings with defects of various character (geometry, depth, general versus isolated pit, well bonded cement, no cement, poorly bonded cement, tension, etc)

- Follow-up to threaded coupling work

- Assessment of non-metallic wellbore tubulars

- Develop operational tool to determine maximum velocity in brine strings to avoid damage to tubulars in caverns. Examine applicability to velocity strings in reservoir storage.

- Review casing vintage/manufacturer relationship to corrosion/defects

\section{Reduced well workover costs}

- Improved casing repair methods - follow-up to assessment of casing repair alternatives

- Examine methods of recycling workover fluids for use in multiple wells

- Improved technology for removing defective casings from wellbores - present brute force methods can be time consuming and uneconomic (ripping, pulling, cutting, milling)

Visit the GSTC web site - http://www.energy.psu.edu/gstc to download this and other GSTC documents. Last modified on March 5, 2007. 


\title{
AWARDS
}

Awards will be made on an annual basis. Subcontracts will be issued from The Pennsylvania State University to the successful applicant. The period of performance for the 2007 funding cycle will be from August 1, 2007 to July 31, 2008. Members will be permitted to submit future proposals to extend the proposed work; however, this must be performed on a year-to-year basis.

If additional documentation is required prior to issuance of a subcontract, a delay in submission of the August 1 start date may occur.

\section{SUBMISSION}

The deadline for receipt of GSTC proposals is May 3, 2007 by 4 PM (Eastern Standard Time). Proposals received after the deadline will be returned to the applicant. Applicants are to submit one original, twelve copies of the proposal, and one electronic copy in PDF format. The full proposal and a separate copy of the public abstract should be saved in PDF format on a CD or ZIP disk and submitted with the paper copies.

In addition to the proposal, each applicant is required to provide the GSTC Membership a nominal 20-minute presentation at the GSTC Spring Meeting which will be held in Buffalo, New York on May 16-17, 2007. The 20-minute presentation will consist of a 15-minute presentation focused on the technical and budget aspects of the proposed project and 5-minute question and answer session. The presentation is due at the time of the proposal submission. The presentation format should be either in the form of an electronic PowerPoint presentation or in the form of overhead transparencies. The proposal packet should be submitted to the following address:

\author{
Mr. Joel L. Morrison \\ Director, Gas Storage Technology Consortium \\ The Pennsylvania State University \\ C-211 Coal Utilization Laboratory \\ University Park, PA 16802-2323
}

If funded, the applicant will be required to provide the GSTC membership with an annual presentation in 2007 and 2008 at the GSTC fall technology transfer meetings in addition to the required reporting requirements.

Visit the GSTC web site - http://www.energy.psu.edu/gstc to download this and other GSTC documents. Last modified on March 5, 2007. 


\section{PROPOSAL FORMAT}

Proposals should be formatted to fit standard $8 \times 11$ " letter size paper with 1" margins, single-spaced, using 12 point font and be consecutively numbered at the bottom on each page.

\section{SECTIONS OF THE PROPOSAL}

The proposal shall consist of the following sections in order.

\section{Proposal Checklist See Attachment A}

The proposal checklist is required to ensure the proposal submittal is complete and that the applicant is eligible for Consortium funding consideration.

\section{Public Cover Page See Attachment B}

The cover sheet along with the public Executive Summary will be distributed to the GSTC membership as part of the proposal evaluation process.

\section{Table of Contents One (1) page maximum}

\section{Public Executive Summary One (1) page maximum}

Provide a one-page summary of the proposed research. The executive summary should not contain any propriety or business sensitive data because summary will be distributed to the GSTC membership along with the proposal cover sheet. An electronic copy of the executive summary is required. The summary will be posted to the GSTC and/or program sponsor websites if the Consortium funds the proposal. The summary should be written in the third person and include a statement of objectives and methods to be employed. It should be informative to other persons working in related fields and understandable to a scientifically or technically literate lay reader.

\section{Technology Overview One (1) page maximum}

The technology overview section of the proposal enables the applicant to discuss how their proposed technology is different from existing technology that may be available within the industry. At a minimum the following should be discussed:

- Is the technology covered by existing patents, and if so, what are they; and

- How does the proposed technology differ from existing technology?

\section{Project Description $\quad$ Five (5) page maximum}

The main body of the proposal should outline the plan of work, including the broad design of activities to be undertaken. At a minimum, the following should be discussed:

- Statement of the problem;

- Has the proposed work, or a portion of the proposed work, been funded elsewhere;

- Objectives and expected significance of the research;

- Statement of the work plan;

Visit the GSTC web site - http://www.energy.psu.edu/gstc to download this and other GSTC documents. Last modified on March 5, 2007. 
- Relation of the proposed work to comparable work in progress;

- Description of available facilities and major items of equipment available for the work; and reference citations.

\section{Project Schedule One (1) page maximum}

A plan which establishes the time schedule for accomplishing the work. The plan should include major milestones of the project in bar chart format and should cover the complete period of performance.

\section{Anticipated Results Two (2) page maximum}

Discuss how the project will improve the integrity, flexibility, deliverability, and costeffectiveness of the nation's underground natural gas/hydrocarbon storage facilities. Discuss the commercial viability of the proposed project. Identify specific groups in the commercial sector that may use the project results.

\section{Previous GSTC-Funded Projects}

One (1) page maximum/ project

If the applicant has been awarded GSTC-funding in previous years, the applicant is required to provide a brief summary of those projects for review. The summary for each project should not exceed one page and should contain the following:

- Project title

- Total level of funding (GSTC funding and applicant cost share)

- Description of how it has benefited the U.S. underground natural gas storage industry.

- List of companies and key contact information for those using the previously funded project results.

\section{Budget See Attachment C}

The submission of a reasonable budget is an important part of the proposal. Your budget may request funds under any of the categories listed on Attachment $\mathrm{C}$, as long as the item and amount are considered necessary to perform the work. Proposed equipment expenditures are permitted; but their purchase must be justified. Ownership of the equipment vests with the Pennsylvania State University and is reported to DOE on an annual basis. It is expected that the participants will already have most of the necessary permanent equipment to conduct the research. The majority of the funding is intended to support research activities. Permanent equipment purchases are discouraged and will be considered during the proposal evaluation. After approval by the Executive Council, but prior to purchase, written approval must be obtained by the Department of Energy for purchase of equipment items that have a life of 2 -years or more and a cost of $\$ 5,000$ or more.

\section{Cost-Share Commitments}

A minimum of $40 \%$ cost-share is required for each project that is selected by the GSTC for funding. The $40 \%$ cost-share is calculated as $40 \%$ of the proposed project (i.e. the sum of the recipient's allowable cost-share and the GSTC share equals the total allowable

Visit the GSTC web site - http://www.energy.psu.edu/gstc to download this and other GSTC documents. Last modified on March 5, 2007. 
costs of the project). Cost-share, which may be in the form of cash and third party inkind, is acceptable as part of the match provided it meets the following criteria:

- Are verifiable, necessary and reasonable for proper and efficient accomplishment of the project;

- Are incurred within the project performance period. Previously expended research development, or exploration costs are unallowable.

- Are not included as contributions for any other federal project, are not paid by the Federal Government under another award, and otherwise allowable in accordance with Federal cost principles and DOE regulations governing cost sharing.

- The value of patents and data contributed to the project is unallowable as cost sharing.

- The value of salaries or wages of $1^{\text {st }}$ party personnel directly involved in the project are allowed as cost share.

All cost-share commitments must be supported by appropriate documentation. Third parties proposing to provide all or part of the required cost share must include a letter from the third party stating it's commitment to provide a specific minimum dollar amount of cost-share. The letter should also identify the type of proposed cost share (e.g., cash, services) to be contributed. Letters must be signed by the person authorized to commit the expenditure of funds and be provided in PDF format. Failure to provide appropriate documentation can result in the proposal being returned without review.

Biographical Sketches

One (1) page per person maximum Vitae of key personnel involved in the project must be included and should include educational background, professional experience, research interest, honors, professional activities and relevant publications.

\section{Letters of Support}

Letters of support from outside sources are encouraged, but not mandatory.

\section{TREATMENT OF PROPRIETARY INFORMATION}

Privileged or confidential commercial or financial information that the applicant does not want disclosed to the public or used by the Government for any purpose other than application evaluation, should be specifically identified by page on the proposal cover sheet.

\section{PROPOSAL EVALUATION PROCESS}

The GSTC Executive Council will review and recommend projects for GSTC funding. The GSTC Director will notify all applicants within thirty (30) days of the GSTC Executive Council meeting, by letter, of the final decision regarding their proposals. The decision of the GSTC is final and not subject to reconsideration or appeal.

Visit the GSTC web site - http://www.energy.psu.edu/gstc to download this and other GSTC documents. Last modified on March 5, 2007. 


\section{ADDITIONAL INFORMATION}

Additional questions should be forwarded to the GSTC Director. Questions should be submitted via e-mail to gstc@ems.psu.edu or contact Mr. Joel Morrison at (814) 8654802. 


\title{
ATTACHMENT A - PROPOSAL PACKET CHECKLIST
}

I certify that:

\author{
$\square$ I am a current Full member of the GSTC \\ $\square$ I am a current University member of the GSTC
}

Project Title:

Principal Investigator (PI):

To assure that your application is complete, please complete and paper clip (one copy only) the proposal packet checklist to the cover sheet of the original (signed) copy of the proposal. Be sure the following items are included in the following order.

Public Cover page completed and signed by PI and authorized representative

Public Executive Summary (one page maximum)

Technology Overview (one page maximum)

Project Description (five page maximum)

Project Schedule (one page maximum)

Anticipated Results (two page maximum)

Previous GSTC-Funded Work (one page maximum/ project)

Budget (Using Attachment $\mathrm{C}$ budget template)

Cost-Share Commitment Letters

Biographical Sketches (one page/ person maximum)

Letters of Support

One signed original copy, twelve copies, and one electronic copy of the proposal in PDF Format are due to the GSTC Consortium no later than 4:00 PM (EST) on May 3, 2007

One electronic copy of the Public Executive Summary in PDF Format

Proposal presentation (15 minute presentation, PowerPoint encouraged)

Visit the GSTC web site - http://www.energy.psu.edu/gstc to download this and other GSTC documents. Last modified on March 5, 2007. 


\section{ATTACHMENT B - PROPOSAL COVER SHEET}

Proposal Submitted to:

Mr. Joel Morrison

Director, Gas Storage Technology Consortium

The Pennsylvania State University

C-211 Coal Utilization Laboratory

University Park, PA 16802-2308

Proposal Deadline:

May 3, 2007 (4:00 PM EST)

Date of Submission

Title of Proposal:

Company Name:

Principal Investigator:

Phone:

Fax:

Email

Address:

Other Participants:

Amount Requested from GSTC

Cost Share Commitments

(Minimum 30\% Required)

Total Project Costs
$\$$

Cash \$

In-Kind

$\$$

$\$$

Visit the GSTC web site - http://www.energy.psu.edu/gstc to download this and other GSTC documents. Last modified on March 5, 2007. 
PROPRIETARY INFORMATION: Does this proposal contain Proprietary or Confidential Information?

NO YES (if yes, complete box below)

\section{Notice of Restrictions on Disclosure and Use of Data}

The data contained on pages of this proposal are submitted in confidence and contain privileged or confidential commercial and/or financial information. Such data may be used or disclosed only for evaluation purposes. If funded, the Government would have the right or use or disclose data from this project to the extent provided the DOE/PSU Cooperative Agreement. This restriction does not limit the Government's right to use or disclose data obtained without restrictions from any source, including the proposer.

Submitted by:

Signature of PI
Approved by:

Authorized Representative

Visit the GSTC web site - http://www.energy.psu.edu/gstc to download this and other GSTC documents. Last modified on March 5, 2007. 


\section{ATTACHMENT C - BUDGET}

$\underline{\text { Salaries and Wages }}$

List individually all personnel identified in the proposal.

Include title and percent of effort

NOTE: The use of undergraduate and graduate students is encouraged, and appropriate.

The basis for proposed percent of effort or labor hours should be identified (historical hours, engineering estimates).

Fringe Benefits

Materials and Supplies

List types required and estimated costs.

NOTE: State whether amounts proposed are based on catalog prices or other cost estimating.

\section{Equipment}

Items exceeding $\$ 5,000$ and 1 year's useful life are defined as permanent equipment. List item and dollar amount for each amount. Justify and/or provide quotation.

Travel (see Note 4)

State the type and extent of travel and its relation to the project. Itemize by destination and estimated costs.

Publication/Information Dissemination Estimate costs of documenting, preparing, publishing and sharing research findings. Show estimates.

Other Direct Costs Itemize and justify. $(*$ See note below)

\section{Facilities and Administration (F\&A)}

Specify current rate(s) and base.

Note: A copy of the negotiated agreement should be included with the proposal. If none exists, a disclosure of the contents of the rate should be made.
$\$$

Name of PI:

$\$$

$\$$

$\$$

$\$$

$\$$

$\$$

$\$$

$\$$

TOTALS

\section{Attach up to two additional pages of justification covering all items.}

Visit the GSTC web site - http://www.energy.psu.edu/gstc to download this and other GSTC documents. Last modified on March 5, 2007. 


\section{*NOTES:}

1) If more than 5\% of project cost is from GSTC funding the contracting organization must be a Full or University Member of the GSTC.

2) Subcontracts included in proposal (third party agreements) to current consortium members must be less than $50 \%$ of the requested GSTC funding. Budgets and work statements from each subcontractor, in the format above, must be included in proposal.

3) Fees or profits will not be paid on any award resulting from this solicitation. Nor can fee or profit be considered as cost-sharing.

4) The GSTC is planning to host two technology transfer workshops in 2007 and 2008. Recipients of GSTC funding are required to provide a presentation on the status of their project at these meetings if requested. The costs of attending these GSTC technology transfer meeting are to be included in the travel budget.

Visit the GSTC web site - http://www.energy.psu.edu/gstc to download this and other GSTC documents. Last modified on March 5, 2007. 